Dr. Mary Frefman, Perrine, Fla,: Some one called attention to the fact that cherry red lips indicate hyperacidity, and in my early practice I used blue litmus paper in the mouth to find out whether the saliva was normal or acid. In the majority of cases in which there is disturbance of the alimentary tract I found a very marked hyperacidity; and now I can almost always tell by the cherry red lips and the tongue, when a child is brought to the office or seen for the first time, that there is hyperacidity present. I had used sodium bicarbonate, and I am glad to hear of Dr. Kerley's suggestion of using bismuth. I have also used aromatic cascara after meals. But the blue litmus paper in the mouth will point the direction in which one is going.

Dr. Harry Lowenburg, Philadelphia: That part of Dr. Kerley's paper which deals with the relationship of hyperacidity to anorexia is extremely important and enlightening to me. I think that all of us come in contact with a vast army of children who are brought by their mothers because they will not eat. For my part, I have taken refuge behind the psychic element and have usually confined my advice to a lecture to the parents and to the grandparents and whoever else may form the environment; but Dr. Kerley's reference to hyperacidity as a cause of the anorexia gives us something more tangible to work on, especially since these parents bring the children to us with the hope that we may do sonething for them aside from reading to them a moral lecture, which usually is of no avail. I think I can plead guilty with a great many others of suspecting worms and many other conditions which perhaps can be ascribed to the hyperacidity to which Dr. Kerley makes reference. My own experience is rather in keeping with that of Dr. McCleave, that is, that not all children who have abnormalities as revealed by roentgen study are the subject of symptoms. I have in mind particularly the son of a physician, who was brought to me by his father, fearing that he had tuberculous peritonitis by reason of the fact that he had large masses in his abdomen, which were readily palpable. In fact, they were so palpable that the boy thought they were bones. This boy proved to have Hirschsprung's disease, of extreme degree, and yet his attitude of living and complexion certainly gave the lie to us who believed that all headaches and obscure pains are due to constipation. I removed from this lad just exactly 17 ounces of feces; and yet he never suffered a symptom. His cecum was so dilated and heavy that it fell over on the left side. The most important part of this paper is the calling of attention to the association of obscure symptoms with the hyperacidity.

Dr. Frank B. Hollenbeck, Lincoln, Neb.: I should like to ask Dr. Kerley what attitude he would assume on the midmorning and midafternoon feeding of milk which is so frequently given in schools in the malnutrition cases.

Dr. Charles Gilmore Kerley, New York: I do not for a moment want to have it inferred that every child who had gastroptosis or abnormalities of the intestinal tract necessarily showed symptoms, or that those cases invariably showed hyperacidity. The point I wish to make is that in these cases of hyperacidity we had these factors present, and the recognition of these factors, plus treatment, is sufficient to give relief very promptly through medication, diet, support of the abdomen, and postural treatment. We not only raise the foot of the bed, but make the child rest on his right side for an hour after meals in the bad cases of stomach ptosis. In addition to that we give a dry meal. We do not give fluid with the meals. We give a dry breakfast and give milk at $11 \mathrm{a} . \mathrm{m}$. and at $3: 30 \mathrm{p}$. m. so as to overcome the overload. The etiology dates back to infancy. They were bottle-fed children, who had been given 8,10 or 12 ounces of food every two or three hours-a continuous overload with resulting ptosis. There are some children with ptosis that will never show symptoms; others will not until they are 10 or 12 years of age, and others, perhaps, not until they are 25 years old; but when one has such a case with associated symptoms, it is well to recognize it, and then one is in a position to use supportive measures, and carry the case through to a satisfactory conclusion. I have examined a considerable number of ptosed stomachs, tested them out with ordinary meals and with the bismuth test meal, and then we have checked them up. The child has always been given the credit of a normal digestive tract, and when abnormalities are discovered in later life, they have been thought to be due to occupation. incorrect posture and other causes. That the gastric intestinal abnormalities of later life are of congenital origin, in part, or have been acquired in childhood has never been appreciated. These patients have been through different hands. They come to me because they do not grow, and cannot keep up play with their fellows. They fail to show proper growth, as their nutrition is always involved. Hyperacidity is invariably a secondary affair. I do not believe that there is such a thing as a primary hyperacidity in a child. In causing hyperacidity in children, two factors are operativestomach abuses and malposition, and the roentgen ray is the only means we have of registering mechanical defects.

\section{COAGULABILITY OF THE BLOOD DURING PREGNANCY AND IN THE NEW-BORN *}

\section{FREDERICK HOWARD FALLS, M.D. IOWA CITY}

The coagulability of the blood has been studied by a number of physiologists and clinicians in recent years. The reason for this is the great practical importance of hemorrhage as a complication of both medical and surgical conditions. Of the various branches of medicine, none has a more frequent incidence or more serious forms of hemorrhage than obstetrics.

The hemorrhages that the obstetrician may be called on to deal with fall naturally into two classes: maternal, and those occurring in the new-born. Every pregnant woman may have antepartum, intrapartum or postpartum hemorrhage. The blood loss varies from the few hundred cubic centimeters that are lost after every delivery to serious bleedings that may cause a fatal termination in a few minutes. The frequency of bleeding sufficiently severe to be termed a pathologic loss of blood is variously estimated by different authors, but it is safe to say that such bleeding occurs in about 3 per cent. of all cases. The amount lost varies from 500 c.c. to 2 liters or more. The pathologic significance of such blood loss is, according to Williams, ${ }^{1}$ slight in the majority of cases, for he believes that the pregnant woman is protected in some obscure way against the deleterious effects of the hemorrhage which, in the nonpregnant woman, would result in grave symptoms. However, he cites cases in which relatively small hemorrhages gave rise to extremely serious symptoms and even death.

Hemorrhages occurring in obstetric cases may be divided into two groups or classes:

1. In the mechanical group, physical defects or alterations of the tissues give rise to a failure of the usual physical mechanism that checks hemorrhage, although the coagulation mechanism may be perfectly competent. Into this group fall cases of abortion; placenta praevia; abruptio placentae; ruptured uterus; ectopic pregnancy; postpartum hemorrhages due to atony, primary or secondary, of the uterine musculature, cervical tears, and rupture or varicose veins of the vagina and vulva. The mechanical factor is relatively frequent in the child following an insecure tie of the cord or a circumcision with improper suture or no suture at all, as in the children circumcised by mohls.

2. In the chemical type, the underlying factor is a failure of the blood to clot firmly in the normal

* From the department of obstetrics, State University of Iowa, and

Otho S. A. Sprague Memorial Institute, Chicago.
1. Williams, J. W.: Am. J. Obst. 80:1 (July) 1919. 
physiologic time limits under normal conditions. This type of hemorrhage is seen almost entirely among babies. The cases occur practically always during the first two weeks of life. Bleeding occurs in the form of capillary hemorrhages, and may come from the nasal mucosa, stomach, bowel, urinary tract, umbilical cord or from a circumcision wound. The chemical type of hemorrhage is very rare in the mothers, and I have seen it only in women who have suffered from a severe mechanical hemorrhage which so depletes the elements necessary for coagulation in the blood that the patient continues to bleed even after the mechanical factor has been removed. This accords well with the fact that hemophilia is very rare in the female members of a family, but is transmitted through them to the male nembers.

This work was undertaken to throw some light on several points:

1. To establish some figures for the coagulation time in normal pregnant and puerperal women and in newborn infants.

2. To determine whether differences exist in the coagulation time of the blood of the mother and fetus at the time of delivery.

3. To determine whether hemorrhagic tendencies in the mother could be detected from a study of the coagulability of the blood at or before the birth of the baby, and a postpartum hemorrhage prognosticated before the bleeding began.

4. To determine whether the coagulation time of the baby's blood at birth would give a clue to the probable occurrence of hemorrhages in the next few days.

5. To determine whether the predisposition to postpartum hemorrhage following ether anesthesia in olsstetric cases is due to alterations in the coagulability of the blood.

\section{TECH NIC}

The technic used was essentially that of Howell, and was adopted so that the results obtained might be compared with his and with figures obtained by others

'TABI.F 1.-COAGULATION TIME OF MOTHER'S BLOOD ANTEPARTUM

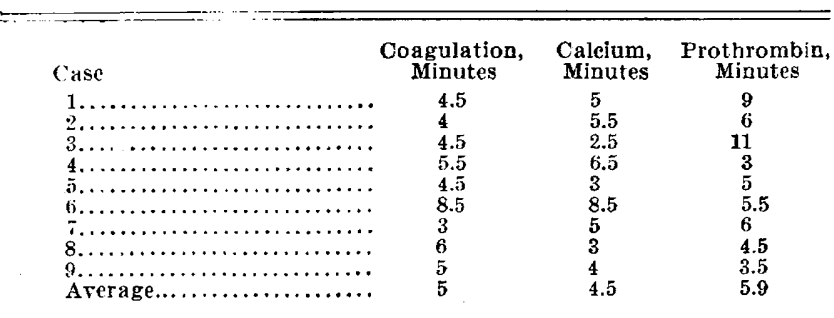

using his methods. From a study of the literature on coagulation of the blood, one is struck with the multiplicity of methods and their divergent results, rendering the work of the different writers valueless for comparison. The technical difficulties of making accurate determinations by any method are great enough as it is, and the results obtained are relative, not absolute, so that a standard technic is desirable to minimize the discrepancies.

Three factors were determined in these experiments: calcium time, coagulation time and prothrombin time.

The coagulation time was estimated by placing 1 c.c. of whole blood in a tube recently rinsed with physio-

2. Howell, W. H.: Harvey Lectures, 1916-1917. logic sodium chlorid solution, and tilting the tube to the horizontal every half minute until the tube could be inverted without losing the clotted blood.

The calcium time was estimated by adding 1 c.c. of whole blood to 6 drops of a 0.5 per cent. solution of calcitum chlorid and tilting the tubes in the same manner as for the coagulation time, and reading the end point in the same manner.

The prothrombin time was determined by placing 0.5 c.c. of a 1 per cent. solution of potassium oxalate in a centrifuge tube and adding about 4 c.c. of whole

TABLE 2.-COAGULATION TIME OF MO'THFR'S BLOOD IN'TRAPARTUM

\begin{tabular}{|c|c|c|c|}
\hline Case & $\begin{array}{l}\text { Coagulation, } \\
\text { Minutes }\end{array}$ & $\begin{array}{l}\text { Calcium, } \\
\text { Minutes }\end{array}$ & $\begin{array}{c}\text { Prothrombin, } \\
\text { Minutes }\end{array}$ \\
\hline 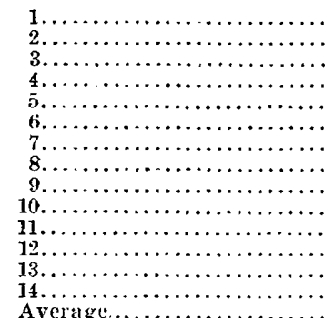 & $\begin{array}{l}5 \\
4.5 \\
4.5 \\
6 \\
5.5 \\
3.5 \\
5 \\
5 \\
4 \\
6.5 \\
3 \\
3 \\
4 \\
7 \\
4.75\end{array}$ & $\begin{array}{l}4.5 \\
4 \\
4 \\
5 \\
6.5 \\
4 \\
6.5 \\
3 \\
6 \\
5 \\
2.5 \\
3.5 \\
2 \\
5.5 \\
4.43\end{array}$ & $\begin{array}{l}4.5 \\
2.5 \\
2 \\
4 \\
4.5 \\
3.5 \\
6 \\
3 \\
2.5 \\
2.5 \\
4 \\
7 \\
4 \\
3.5 \\
3.82\end{array}$ \\
\hline
\end{tabular}

blood. This was mixed thoroughly and centrifuged for ten minutes at moderate speed, and the clear plasma was used for the determinations. Seven tubes were rinsed with physiologic sodium chlorid solution and placed in a rack. To Tube 1 was added 2 drops of a 0.5 per cent. solution of calcium chlorid. To Tube 2 was added 3 drops and so on, until the seventh received 8 drops of the calcium chlorid solution. Five drops of the oxalated plasma was added to each tube, and the time and tube noted at which the coagulum first appeared. The end-point was determined by tilting the tubes every half minute, as in the case of the calcium and coagulation time estimation.

The blood was obtained from the mothers by puncture of the median basilic vein, and drawn into a Luer syringe which had been rinsed with physiologic sodium chlorid solution immediately before the blood was drawn. The fetal blood was obtained by puncture of the vein of the umbilical cord, in most cases just before or just after the cord was clamped, but in a few cases from a few minutes to half an hour after the delivery of the placenta. Some investigators have used blood from the cut end of the cord, but this is hardly comparable to blood obtained by venipuncture because of the presence of Wharton's jelly and thrombokinase set free from the cut surface of the cord. In all cases the readings were made immediately after the samples were obtained, and an attempt was made to provide uniform conditions as to temperature and moisture to avoid variations in results due to these factors.

\section{RESULTS}

From a study of the figures it would seem that the coagulation time of the blood is not prolonged beyond the normal in pregnant, parturient or puerperal women. Table 1 shows the results of tests made on pregnant women not in labor. It is seen that the average coagulation time was 5 minutes, calcium time 4.5 minutes, and prothrombin time 5.9 minutes. These figures are well below the upper limit of 8 minutes 
set as the coagulation time of normal blood. Incleed, it would seem that a slight increase in the coagulability of the blood occurs in pregnancy.

Table 2 gives the restults of the tests made while the woman was in active labor, and in most cases only a few hours or minutes before the birth of the baby Theoretically, it might be assumed that the marked physical strain of labor, together with the more obscure, but nevertheless significant, changes in the physiologicochemical constituents of the blood at this time, might have a marked effect on the coagulation time. However, it will be seen from the figures that the

TABLE 3.-COAGLLATION TTME OF MOTHYR'S BIOOD POSTPARTUM

\begin{tabular}{|c|c|c|c|}
\hline Case & $\begin{array}{c}\text { Coagulation, } \\
\text { Minutes }\end{array}$ & $\begin{array}{l}\text { Calcium, } \\
\text { Minutes }\end{array}$ & $\begin{array}{l}\text { Prothrombin, } \\
\text { Minutes }\end{array}$ \\
\hline 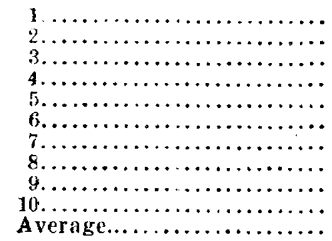 & $\begin{array}{l}3 \\
6 \\
5 \\
6.5 \\
5.5 \\
7 \\
7 \\
6 \\
3.5 \\
4 \\
5.3\end{array}$ & $\begin{array}{l}2 \\
5.5 \\
5.5 \\
7.5 \\
6.5 \\
8 \\
6 \\
6.5 \\
4 \\
5 \\
5.65\end{array}$ & $\begin{array}{l}10 \\
4.5 \\
4.5 \\
4 \\
4 \\
2 \\
2.5 \\
2 \\
3.5 \\
2 \\
3.5\end{array}$ \\
\hline
\end{tabular}

average coagulation time was approximately the same as in the preceding series, 4.75 minutes. The calcium time was 4.43 and the prothrombin time 3.82 minutes. These figures are slightly less than those in Table 1 ; the difference is not striking enough, however, to warrant drawing conclusions.

Table 3 shows the results obtained from the coagulation time determinations on the blood of women luring the puerperium and during lactation. The figures indicate that the coagulation time is about the same as for pregnant women and for women in labor. The average coagulation time was 5.3 minutes, calcium time 5.65 , and prothrombin time 3.5 minutes.

Table 4 shows the results obtained from the coagulation time determinations on the blood of the new-born babies. The average coagulation time was 4.5 minutes, calcium time 3.75 , and prothrombin time 3.5 . In this series the blood was obtained from the umbilical cord by venipunture as soon as possible after the delivery of the baby. In two cases the blood was obtained fourteen and thirty minutes, respectively, after the placenta was expelled. The coagulation, calcium and prothrombin time was not materially altered in these cases.

None of the babies of this series proved later to be bleeders, so that a statement regarding the coagulation time in this class of cases at the time of birth cannot be made. However, the opinion is ventured, and is supported to some extent by the work of Rodda, that even in these cases the coagulation time is normal at birth.

The prothrombin time estimation in some of the cases was very difficult, owing to the fact that while a clot formed in these cases, it was not very firm, and it was difficult to determine just when it had reached its maximum density.

\section{COMMENT}

It would seem from a consideration of these figures that the blood coagulation time in women before; during or after delivery is well within the normal limits, and that blood taken during labor, just before the birth of the baby, coagulates a little more quickly.
These results accord very well with those of Myer Solis Cohen, ${ }^{3}$ who made his coagulation observations on drops of blood in a Stender dish at constant temperature on a water bath. He found that menstruation and pregnancy caused no change in coagulation, and that the puerperium decreased the coagulability of the blood slightly. He found also that the intake of fluids decreased the coagulability of the blood, and that the coagulation time was prolonged after meals.

Weiss ${ }^{4}$ found that the coagulation time in the newborn was less than the average for the adult, as measured by the Wright method, and, as was seen in these experiments, was frequently the same as that of the mother's blood. In some instances it was delayed, but in these cases the coagulation time of the mother's blood was also delayed. He also found that breast-fed babies had a longer coagulation time than those fed on cow's milk. He ascribed this to the fact that cow's milk contains more calcium and magnesium than mother's milk.

Rodda " found that the average coagulation time in new-born infants was seven minutes, and ranged from five to nine minutes. His method consists in placing a drop of blood between two watch crystals and rolling a lead shot through the drop till the shot is caught by the coagulum. He noted that the coagulation time was progressively prolonged till the fifth day, and that it returned to normal by the tenth day. This corresponds to the clinical observation that most of the spontaneous hemorrhages seen in the new-born occur from the second to the eighth day.

The addition of calcium to the blood seemed to increase the coagulability, but not sufficiently to be accounted a significant factor in the hemorrhages of the new-born. This agrees with the work of Emmel, ${ }^{6}$ who found that the calcium content of pig embryos was in excess of that in adults in the proportion of $7: 5$. He noted also that the presence of bile in the blood of these embryos is the primary factor in the increased coagulation time. This, he found, could be

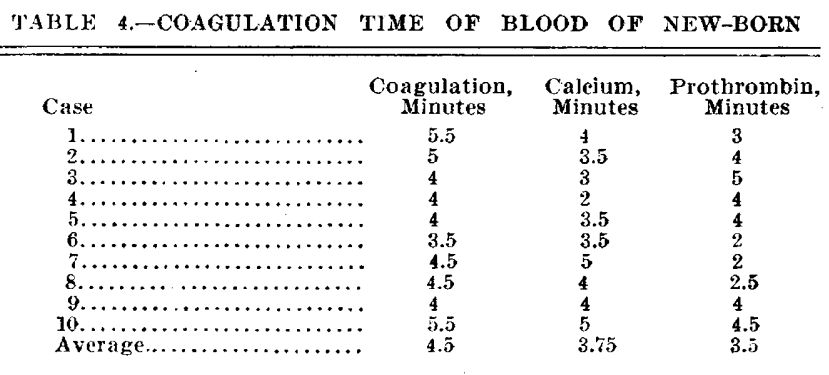

overcome by the addition of tissue juice, which neutralized the action of the bile. He noted that the blood platelet count was about the same in the embryos as in the adult pigs. The clots obtained were loose and of the sliding type, as opposed to those in my series, which were as firm as the clots observed in the adult bloods. The babies in this series were all full-term.

It is seen from a comparison of the coagulation time of the maternal and fetal blood, as shown in Table 5, that at the time of birth there is very little difference. In most cases, if the coagulation is retarded in one, a

3. Cohen, M. S.: The Coagulation Time of the Blood as Affected by Various Conditions, Arch. Int. Med. 8:684 (Nov. 15) 1911.

4. Weiss, Hugo: Wien. klin. Wchnschr. 23: 839, 1910 . Born, Am. J. Dis. Child. 19:269 (April)

6. Emmel, V. E.: J. Exper, Med. 31: 177 (Feb.) 1920. 
similar change is noted in the other, though it may be less marked. These facts would argue that there is probably a free exchange, through the placenta, of the substances that enter into the reaction of coagulation. This, in turn, shows why the hemorrhages of the newborn rarely, if ever, occur on the first day of life, but are usually seen about the fourth day.

Postpartum hemorrhages have been observed clinically much more frequently in patients who have been 1under ether anesthesia than in patients who have not

TABI.F 5.-COMPARISON OF MATERNAL AND FETAL BLOOD

\begin{tabular}{|c|c|c|c|c|}
\hline Blood & Case & $\begin{array}{c}\text { Coagulation, } \\
\text { Minutes }\end{array}$ & $\begin{array}{l}\text { Calcium, } \\
\text { Minutes }\end{array}$ & $\begin{array}{l}\text { Prothrombin } \\
\text { Minutes }\end{array}$ \\
\hline Maternal............. & 1 & 3 & 2.5 & 4 \\
\hline Petal................ & 1 & 3 & 3 & No good clot \\
\hline Maternal.............. & 2 & 4 & 4 & 4 \\
\hline Fetal................. & 2 & 4 & 2 & 4 \\
\hline Waternal.............. & 3 & 5 & 6.5 & 6 \\
\hline Fetal................ & 3 & 3.5 & 3.5 & 2 \\
\hline Maternal.............. & 4 & 6.5 & 5.5 & 4.5 \\
\hline Fetal............... & 4 & 5 & 5.5 & 4.5 \\
\hline Maternal............... & 5 & 3.5 & 4 & 3.5 \\
\hline Fetal................ & 5 & 6 & 7 & 4.5 \\
\hline Maternal.............. & 6 & 5 & 3 & 3 \\
\hline Fetal.................. & 6 & 5.5 & 4 & 3 \\
\hline Maternal............. & 7 & 4.5 & 4 & 2.5 \\
\hline Fetgl................ & $\tau$ & 4.5 & 4 & 2 \\
\hline Maternal.............. & 8 & 4.5 & 4 & 2 \\
\hline Fetal............... & 8 & 4.5 & 4 & 2 \\
\hline Maternal............ & 0 & 6 & 4 & 4 \\
\hline Fetal............... & 9 & 4 & 4 & 4 \\
\hline Maternal............. & 10 & 3 & 3.5 & 7 \\
\hline Fetal................... & 10 & 4 & 3 & 5 \\
\hline
\end{tabular}

been anesthetized. This factor was observed in all cases, but no differences in the coagulation time could be detected in the two groups. It is probable, therefore, that these hemorrhages are due to relaxation of the uterine muscle bundles, thus releasing the constriction on the uterine vessels.

\section{CONCLUSIONS}

1. The coagulability of the blood in women before, luring and after labor, as measured by the estimation of the coagulation, calcium and prothrombin time, is well within the limits of normal blood coagulability

2. Maternal and fetal blood at the time of birth of the baby have practically the same coagulation time.

3 . There is no evidence from this series of experiments that pregnancy tends to produce a hemophilic state in the mothers; hence, postpartum hemorrhage can rarely, if ever, be ascribed to this cause.

4. Fetal blood at birth clots with normal firmness and rapidity, so that subsequent hemorrhagic tendencies cannot be detected from coagulation tests at this time.

5. Patients who took ether exhibited the same coagulition time as those delivered without ether. Postpartum henorrhages, therefore, which are more common in these cases, cannot be explained on the basis of decreased blood coagulability.

Infant Mortality and Prevention in New Zealand.-The result of a study made by the U. S. Department of Labor (children's bureau) shows a close relation between organized infant welfare work and a striking reduction in the number of infant deaths in New Zealand. The New Zealand rate is lower than that of any other country in the world, it is stated. For 1919, the number of deaths of infants under 1 year of age was only 45 to every 1,000 live births, as compared with 87 in the United States birth registration area. The credit for this is due to the work of the Royal New Zealand Society for the Health of Women and Children, organized in 1907. Popular education in "mother-craft" is also promoted, through free distribution of pamphlets; publication in the newspapers of a regular column on "Our Babies," and the natural passing on of information among the women of the society.

\section{BATTERY BURNS}

REPORT OF THREE CASES

HARRY S. GRADLE; M.D. CHICAGO

There have come under my observation, during the last two years, three cases of burns of the eye and adnexa by sulphuric acid from storage batteries. The burn in itself in each case has presented no clinical features unusual to any acid burn; but the interesting feature has been the manner of production. All of the cases have been in mechanics working on the storage batteries of automobiles, and a few brief facts concerning such batteries would not be amiss.

A storage battery consists of an acid-proof cell, containing alternate plates of lead and zinc and filled with dilute sulphuric acid. The cell has an acid-proof cover, through which three vents lead, two of them closed by the usual electrode connections, while the third is for ventilation and is usually closed by a rubber screwcap with a pinhole aperture in it. Such a battery is continuously charging or discharging, and is never electrically quiet unless completely inert.

During the process of charging, heat is generated by the resistance of the fluids to the electrical current, and hydrogen is given off by an electrolytic change in the sulphuric acid. When the battery is at an electrically low ebb, the amount of heat and hydrogen given off is very minute; but as the point of electric saturation approaches, the heat increases in amount so that a fully charged battery has a temperature at its point of saturation as high as $140 \mathrm{C}$. $(284 \mathrm{~F}$.). At this point, the hydrogen is given off in such quantities that visible bubbles appear in the battery solution, and the battery is said to be "gassing." And this is the dangerous point. An open flame of any sort, whether it is an electric spark, a blow-torch, or a glowing cigaret, suffices
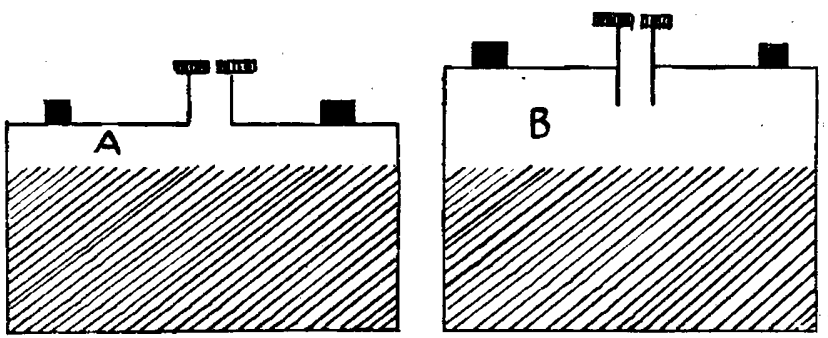

Batteries in cross-section, with small dead space $(A)$ and large dead space ( $B$, dangerous type).

to ignite the hydrogen that has been mixed with air, and the gases will burn with an almost instantaneous flame. Were this in the open and unconfined, there would be no danger. But the flame occurs within the small air chamber that lies within the battery cell between the upper level of the sulphuric acid and the cover of the cell. Confined within this small space, the rapidity and intensity of the gas flame is sufficient to be regarded as an explosion, exerting tremendous pressure equally in all directions. The sole vent is the aperture for ventilation (and the cap is usually off), and through this are driven the burned and burning gases and quantities of sulphuric acid that lie near the surface.

The force is sufficient to drive the mixture several feet into the air, and woe betide the flesh that lies. 